\title{
The authorship of disguised handwriting written with the unaccustomed hand: A preliminary study
}

\author{
ANITA RANI \\ ORCID: 0000-0002-8928-223X \\ Formerly Senior Research Fellow, Department of Forensic Science \\ Punjabi University, Patiala \\ MOHINDER SINGH \\ ORCID: 0000-0002-2649-1616 \\ Formerly Government Examiner of Questioned Documents \\ Central Forensic Science Laboratory, Hyderabad, India

\section{OM PRAKash Jasuja} \\ ORCID: 0000-0002-2221-1242 \\ Department of Forensic Science, Chandigarh University \\ Gharua, Punjab, India
}

\begin{abstract}
Sometimes, a writer may try to disguise their normal handwriting to hide their identity. One of the most effective and less frequent modes of disguise is to write with the unaccustomed hand. In this type of disguise, due to a sudden loss of pen control, pictorial appearance of handwriting changes to such an extent that the writer assumes success and gets convinced that the disguised handwriting they have produced cannot be attributed to them by comparison with their normal writing style. In the present study, handwriting samples of several persons, both with the normal hand and the unaccustomed hand, were obtained and an attempt has been made to find out and identify those features that
\end{abstract}


survive the hazards of disguise and could be helpful to accurately determine the authorship of such disguised handwriting in comparison with one's normal handwriting samples. A detailed study of letter-forms, the connecting strokes between letters, and t-crossing written by several persons has been carried out. It has been found that, despite pictorial dissimilarities, there are certain unconscious features that are rarely disguised which could either form the basis for their association with a particular writer or indicate its probability for further investigation. The analysis, comparison, and evaluation of features unconsciously left by the writer, including the parameters selected for the present study, can be carried out by a trained forensic document examiner; and they can give whatever opinion is possible and justifiable in facts and circumstances of a case.

Keywords: forensics, handwriting, disguise, unaccustomed hand, authorship, identification

\section{Introduction}

Handwriting is an acquired skill that can be neither discarded nor developed at will. Particularly at the stage of graphic maturity, the production of natural handwriting becomes so automatic that it does not require any conscious direction. All the master patterns of handwriting that are acquired and practiced become fixed in the brain and, during the process of writing, they are retrieved and physically produced on paper by human hand through the muscular system. Being a neuromuscularly controlled motor activity, the production of natural handwriting is almost automatic; the writer does not need to concentrate on how to write, they rather concentrate on what to write. Once the writing habits get fixed, it becomes difficult for a writer to either successfully disguise their own handwriting or to forge somebody else's. Though it is difficult to maintain consistently, some of the writers still attempt to disguise their handwriting, with the possible objective of hiding their identity for subsequent denial. Not only are these cases frequent, but also people adopt novel methods of disguise, principal among them being: a change of slant, a change of size, substituting letter forms, using block capitals, opposite-hand writing, inverted writing, using a broad tip pen, or a change in speed of writing. Several features of disguised writings, including the line quality defects, are well documented ${ }^{1}$ and through them it can be determined whether or

${ }^{1}$ A.S. Osborn, Questioned documents, Rochester, NY 1929, p. 34; W.R. Harrison, Suspect documents: Their scientific examination, London 1958, pp. 365-369; O. Hilton, 
not the handwriting is disguised. ${ }^{2}$ Harrison $^{3}$ has reported eight general principles for detection and identification of disguise that are still relevant and being followed by forensic document examiners.

Most of the attempts to disguise handwriting are ineffective and can be detected, though the writers assume they can achieve that by simply changing the pictorial effect of handwriting. They are perhaps unaware of some unconscious writing habits that are involuntarily reflected in their handwriting. An interesting observation reported by Harrison is that only one out of nine people (i.e. about $11 \%$ ) can change their handwriting appearance to the extent that makes it impossible to identify at a glance. Furthermore, the average writer cannot consistently maintain the disguise for a considerable length of time. As soon as the attention given to the writing process is unconsciously withdrawn, the writer reverts to their normal writing style.

Handwriting could more appropriately be called brain-writing, because a hand only acts as a servant of the brain. Therefore, theoretically speaking, the production of writing is almost independent of the physical part that brings it on paper, be it the right hand or the left hand. As stated by Harrison, ${ }^{4}$ developed handwriting is substantially the unconscious product of the mind; it is, therefore, independent of the hand that produced it. Although some of the writers could be ambidextrous too, most writers favor one hand over the other and have accordingly developed their own pen control, muscular coordination, and writing skill with respect to the dominant hand. When writing with the opposite hand or the unaccustomed hand, the writer loses their rhythm and muscular control, resulting in inferior quality of handwriting, which some of the writers consider as an effective disguise, capable of hiding their identity. Because the pictorial effect produced by unaccustomed-hand writing is considerably different from that of the accustomed hand; most of the time the writer prefers

Scientific examination of questioned documents, New York 1982; K.M. Koppenhaver, Forensic document examination: Principles and practice, Totowa, NJ 2007; E.F. Alford, "Disguised handwriting: A statistical survey of how handwriting is most frequently disguised", Journal of Forensic Science 15, 1970, no. 4, pp. 476-488.

2 K.M. Koppenhaver, op. cit.

3 W.R. Harrison, op. cit.

4 Ibid. 
to use the unaccustomed hand as a mode of disguise. ${ }^{5}$ Harrison ${ }^{6}$ has since reported that disguised writing produced by the unaccustomed hand will bear little general resemblance to that written by the dominant hand; and about 5\% (one in twenty) of the people going for disguise chose writing with the unaccustomed hand as the preferred mode of disguise, since it produced an unrecognizable script.

Some of the features of unaccustomed-hand writing are: lack of muscular control, poor skill, poor line quality, poor rhythm, induced tremor, uneven base line, and abrupt changes in direction of movement while forming loops and circles. Sometimes reverse movement of letter forms could also be found. However, since the master patterns are stored in the brain, handwriting features habitual and peculiar to the individual such as: letter designs, spacing, proportions, initials, terminals, connecting lines, hooks, and ticks, will naturally carry over from the dominant to the non-dominant hand. Therefore, it becomes important to recognize those features in disguised handwriting which could be solely attributed to the unaccustomed hand. Jasuja and Anita ${ }^{7}$ reported several such features. Once the disguise has been detected, the next challenge is to ascertain the identity of the writer. For this purpose, the forensic document examiner needs to compare the questioned writings purportedly written with the unaccustomed hand with the standard writings of the suspect.

Since originality in disguise is rare, it is easily detectable; however, as mentioned above, there are also certain (unconscious) features that are rarely disguised even in unaccustomed-hand writing, which could bear similarities to the accustomed-hand writing of the same person. ${ }^{8}$

5 K.M. Koppenhaver, op. cit.

${ }^{6}$ W.R. Harrison, op. cit.

7 Anita, O.P. Jasuja, "Mirror writing: A trait of writing with unaccustomed hand", Problems of Forensic Science 106, 2016, pp. 444-455.

${ }^{8}$ G.A. Dawson, "An identification of handprinting produced with the unaccustomed left hand", Canadian Society of Forensic Science Journal 26, 1993, no. 2, pp. 61-67; M. Conrad, "Left-hand writing vs. right-hand writing", Journal of the American Society of Questioned Document Examiners 11, 2008, no. 1, pp. 19-27; G.A. Dawson, "Brain function and writing with the unaccustomed left hand", Journal of Forensic Science 30, 1985, no. 1, pp. 167-171; J.E. Franks et al., "Variability of stroke direction between left-and right-handed writers", Journal of the Forensic Science Society 25, 1985, no. 5, pp. 353-370; J.A. Joseph, "Left-hand and opposite-hand writing features useful as a basis 
In addition to these features, there exists a possibility that even more features, such as the design of letters, the connecting strokes between letters, and the inconspicuous t-crossing, may remain unaffected by switching from the dominant hand, which could be helpful in identifying disguised handwriting. It has, therefore, been considered more appropriate to carry out a study to find out and evaluate if such features continue to persist in disguised handwriting produced by the opposite hand. The present study makes an attempt to examine in detail whether the changes in handwriting due to the use of the unaccustomed hand are only superficial, solely affecting the pictorial appearance, or if they are deeply rooted, affecting letter formations and rendering the writing unidentifiable. Additionally, features such as diacritic marks on letters ' $i$ ' and ' $j$ ' and the formation of letter 'o' have also been included in this preliminary study.

\section{Materials and methods}

The vast majority of people are natural right-handers. Left-handers, as reported by Everyday Health, ${ }^{9}$ make up about $10 \%$ of the population, while ambidextrous people, according to Reader's Digest, ${ }^{10}$ constitute only about $1 \%$.

In the present study, handwriting samples were collected from university and college students who were very comfortable with English (Roman) script writing and can be categorized as skilled writers. Out of the 200 volunteer students, 100 were natural right-handers comprising 50 males and 50 females; and the remaining 100 were left-handers, comprising 50 males and 50 females. All volunteers were in the age group ranging between 17 and 32 years. Prior consent was obtained from the volunteers to using their handwriting samples for research purposes. The text selected for the volunteers to write is provided in Figure 1.

of forming expert opinions of authorship", National Association of Document Examiners Journal 2004.

9 K. Kerns Geer, "12 little known facts about left-handers", Everyday Health, 13.08.2015, https:/www.everydayhealth.com/healthy-living-pictures/little-known-factsabout-lefthanders.aspx.

10 M. Jones, "10 fascinating facts you never knew about ambidextrous people", Reader's Digest, 29.05.2019, https:/www.rd.com/list/facts-ambidextrous-people/. 


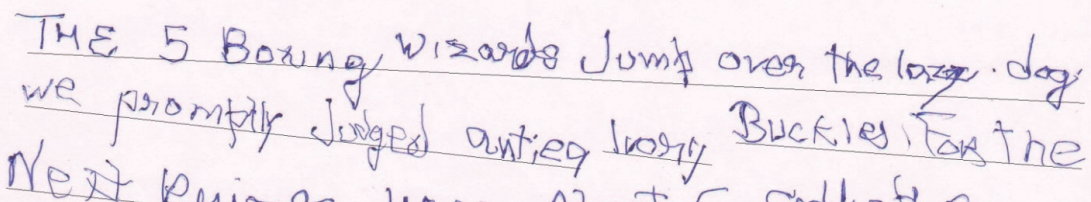 Next Rrizes 4832. About Go Conflst 7908 will make a grater of fiez, fism. I have spatted the 197 womten tin the Jway Bax-our London Bubnger is good But userma - and bublin are giect mpre Roht gone to switzerland conolel Wa, top Krma}

Figure 1. The text selected for the volunteers to write

These handwriting samples were collected in two ways.

1. Copying method: the standard passage was given to the volunteers, who were asked to write with both hands on separate A4 plain sheets.

2. Dictation method: dictation was given to the volunteers, who were asked to write with both hands on separate A4 plain sheets, while each word was repeated three times.

In this way, four handwriting samples were collected from each subject, thus the total number of handwriting samples was 800 .

None of the subjects was given any prior training to write with the unaccustomed hand, nor were they related to one another. A standard passage of handwriting was given to all the volunteers, which included all lowercase as well as capital letters in English (Roman) script and numerals from 0 to 9 (reference Figure 1 above). The handwriting samples obtained from the subjects contained mostly cursive handwriting produced with a ballpoint pen.

Two examiners with 5 and 30 years of research experience in handwriting examination respectively were asked to evaluate the collected handwriting samples. Each sample was examined with the help of a magnifying glass $(10 \times)$ to study the formation of strokes, particularly the connecting strokes in both the accustomed- and unaccustomed-hand writings. The extent of similarity or difference in both types of handwriting samples was observed for each selected feature. 
The authorship of disguised handwriting

15

Features of the connecting strokes were studied in 15 particular letter combinations selected from the passage used for handwriting analysis. These can be found in the words: wizards (ar), the (th), spotted (ot), good (oo), Dublin (li), jelly (ll), prize (ri), business (ss), women (om), about (ab), gone (go), jury (pu), Vienna (Vi), fizzy (ry), and Hongkong (Ho). Similar manners of connecting strokes are marked with red arrows and shown in Figure 2.

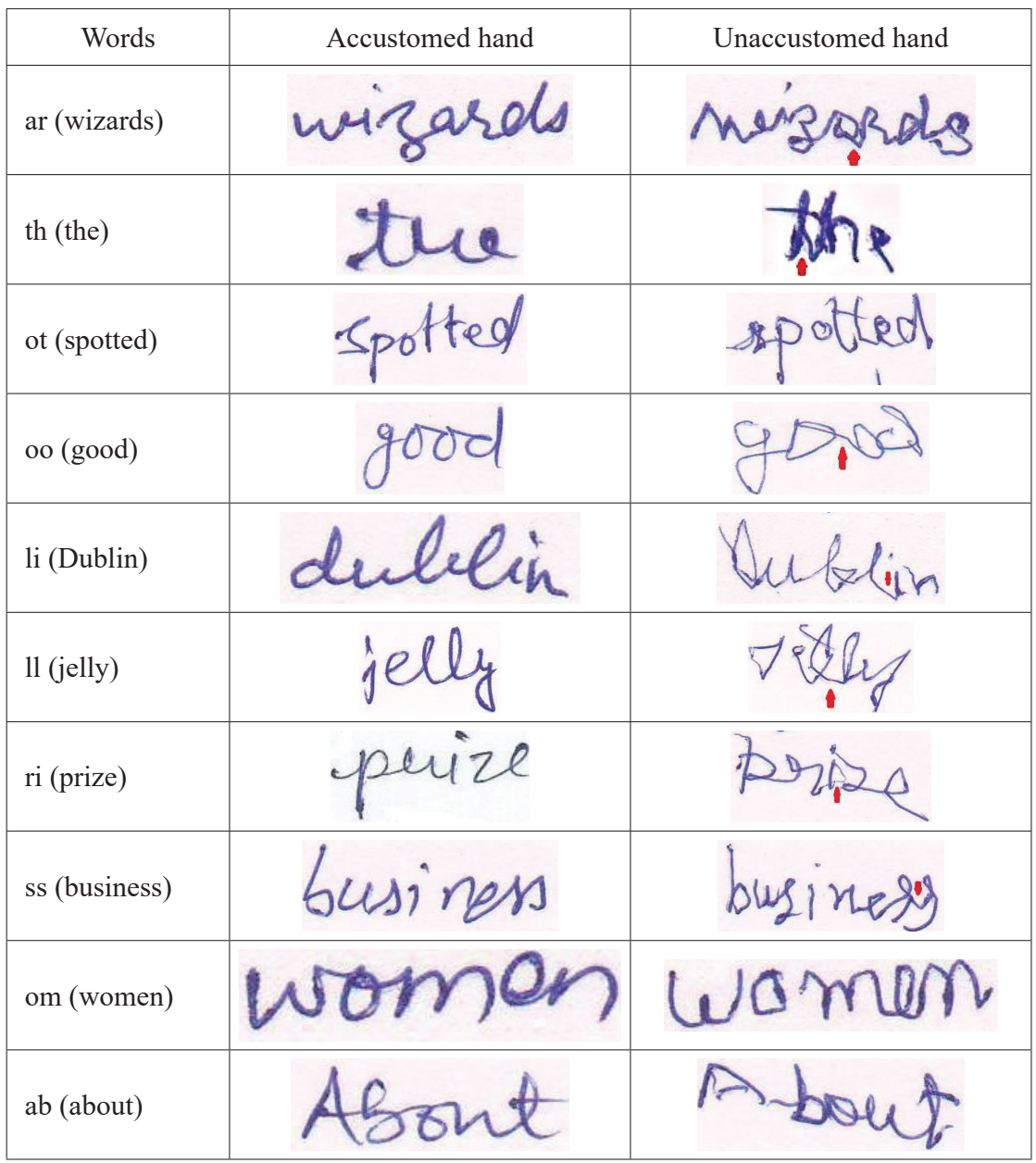

Now Kodyfikacja Prawn Karnego 59, 2021

(C) for this edition by CNS 


\begin{tabular}{|l|c|c|}
\hline go (gone) & gone \\
\hline ju (jury) & jery \\
\hline in (Vienna) & fizzy \\
\hline Ho (Hongkong) & Hong kong \\
\hline
\end{tabular}

Figure 2. Presence of letter connections in both accustomedand unaccustomed-hand writing samples

Additionally, the formation of strokes in particular part of the grapheme and t-crossings were studied. The formation of strokes in ovals and loops was studied in terms of the direction of the pen movement, while $\mathrm{t}$-crossing was studied regarding the direction of the crossing bar over the staff; that is, if it was right to left or left to right. Also, diacritic marks on letters ' $\mathrm{i}$ ' and ' $\mathrm{j}$ ' were studied in terms of their shape and position, while the letter ' $\mathrm{o}$ ' was studied regarding the direction of its stroke formation - clockwise or anticlockwise.

All the results were presented in the form of observations and illustrated with the help of figures. No statistical tools were applied at this stage.

\section{Results and discussion}

\section{Connecting strokes}

In the present study, various letter combinations were selected and the types of connecting strokes were observed in handwritings of both left-handers as well as right-handers. A similar way of connecting the two letters was observed and indicated in Figure 2. However, it has been observed that in accustomed-hand writing the connections are smooth while unaccustomed-hand writing possesses angularities, hesitations, 
abrupt directional changes, hairline connections, uncertain movements, as well as tremulous strokes. This could be due to the poor neuromuscular coordination of the unaccustomed hand, resulting in inferior 'finger' writing movement in the disguised writing. It was consistent with the observation that connections were certainly absent in the unaccustomedhand writings if there were no corresponding connecting strokes present in the accustomed-hand writings. However, connections were also found to be absent in writings with the unaccustomed hand in places where such connecting strokes were present in the corresponding accustomed-hand writings. This is consistent with the statement of Huber and Headrick ${ }^{11}$ that writing with the non-dominant hand displays a loss of skill and fluency as well as reduction in writing speed which may result in a poorer line quality, tremors in writing, abrupt changes in pen pressure, and absence of connections between the letters. Furthermore, Joseph ${ }^{12}$ reported various features of unaccustomed-hand writing such as acute angles in connecting strokes, flattened bottom loops of letters ' $\mathrm{g}$, ' $\mathrm{j}$,' and ' $\mathrm{y}$, ' dragging terminal strokes of letters, low level of skill, tremors and lack of smoothness in line quality, abrupt directional changes etc. Results of the study consistent with similar observations made by the above mentioned authors are presented along with specific reasons for variation, if any.

As far as the type of the connecting strokes is concerned, it was observed that there seems to be very little difference in connecting strokes between writing with the accustomed hand and that with the unaccustomed hand when it was copied from the text; but with the unaccustomed-hand writing in dictation mode, there are unpredictable changes in the connecting strokes, as illustrated in Figure 4. This could be due to the obvious loss of freedom to write as one has to follow the dictation and their attention is diverted from the writing process. Consequently, the writer becomes helpless to move the writing instrument in an unpredictable way. To establish the authorship of disguised writings, there must be significant similarity in execution of strokes in both the questioned and the standard writings. In the present study, no practice or training was imparted to the volunteers to write with the unaccustomed hand; and even

11 R.A. Huber, A.M. Headrick, Handwriting identification: Facts and fundamentals, Boca Raton, FL 1999.

12 J.A. Joseph, op. cit. 
then, some similarities were observed in the formation of the connecting strokes between letters in both sample types. Had the volunteers gotten the opportunity for training and practice before giving their handwriting samples, their level of performance and consequently the results of the analysis could have been much better. ${ }^{13}$

\section{Formation of strokes}

In the present study, letters - namely 'a,' 'k,' 'f,' ' $z$,' ' $\mathrm{j}$,' 'd,' and ' $\mathrm{g}$ ' - were selected to examine the accustomed and unaccustomed-hand writings of both the left-handed and right-handed writers. These letters were taken from the same word in accustomed- as well as unaccustomedhand writings in order to compare both types and see if the writing changes with the change of hand. In the case of unaccustomed-hand writing, most strokes were found to be similar to unaccustomed-hand writing, but the letters showed variations in the form of hesitations, large letter size, angular strokes, etc. in handwriting produced with both the copied and the dictation methods, due to unnatural and uncontrolled holding of the writing instrument (Figure 3). Hilton ${ }^{14}$ reported that in writings created with the unaccustomed hand, same general features of movement and proportion were found, with the exception of a few letters which may be constructed with a different stroke direction. Kelly and Lindblom ${ }^{15}$ reported that writing with the unaccustomed hand affects the writing's pictorial appearance.

Interestingly, wherever a writer wrote the letters with embellishments with their accustomed hand, the same writer while writing with the unaccustomed hand tried to insert the embellishments. It was clearly seen in all the samples of unaccustomed-hand writing. Because the activities of each hand are controlled by the opposite brain hemisphere, when

13 T. Dziedzic, "The development of left-handed writing features of a right-handed person who has undertaken training in writing with his left hand", Problems of Forensic Sciences 83, 2011, pp. 93-102; idem, "Right hand writing vs. left hand writing of one person: A comparative study", Problems of Forensic Sciences 94, 2013, pp. 564-577.

14 O. Hilton, op. cit.

15 J.S. Kelly, B.S. Lindblom, Scientific examination of questioned documents, Boca Raton, FL 2006. 
a writer writes with the unaccustomed hand, proper signals for making the letter designs are not received, as the writer may not be used to writing with the opposite hand.

\begin{tabular}{|c|c|c|c|c|}
\hline $\begin{array}{l}\text { Letter } \\
\text { 'z' }\end{array}$ & $\begin{array}{l}\text { Accustomed } \\
\text { copied }\end{array}$ & $\begin{array}{l}\text { Accustomed } \\
\text { dictation }\end{array}$ & $\begin{array}{l}\text { Unaccustomed } \\
\text { copied }\end{array}$ & $\begin{array}{l}\text { Unaccustomed } \\
\text { dictation }\end{array}$ \\
\hline $\begin{array}{c}\text { Writer } \\
1\end{array}$ & 2 & & & \\
\hline $\begin{array}{c}\text { Writer } \\
2\end{array}$ & $z^{\prime}$ & & $\gamma$ & 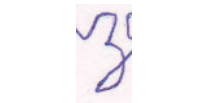 \\
\hline $\begin{array}{c}\text { Writer } \\
3\end{array}$ & & & & \\
\hline $\begin{array}{c}\text { Writer } \\
4\end{array}$ & & & $\otimes$ & \\
\hline $\begin{array}{c}\text { Writer } \\
5\end{array}$ & 12 & ? & 50 & \\
\hline
\end{tabular}

Figure 3. Formation of strokes in samples produced by copying and dictation methods, in both the accustomed and unaccustomed hand writings (right-handed writers)

The formation of strokes in accustomed-hand writing shows similarity in both copied and dictated samples. As is evident from Figure 5, the strokes were found to be similar in accustomed- as well as in unaccustomed-hand writings. However, letters showed variations in the form of hesitations, large letter size, angular strokes, etc. in both copied and dictated samples of unaccustomed-hand writing due to an uncontrolled hold on the writing instrument. This could create confusion while making opinions on authorship.

\section{T-crossing}

T-crossing (t-bar) is a feature which is habitual and personal to every writer. There are generally two ways to make the cross of letter ' $t$ '; from left to right or right to left. But many writers may have the habit of making this crossing stroke in both ways (i.e. left to right as well as right to left) 
in their handwriting. In present study, all the three types of t-crossing have been observed and illustrated through Figure 4, in both accustomed- and unaccustomed-hand writing samples.

Accustomed hand

Figure 4. Habit of t-crossing in both accustomed- and unaccustomed-hand writings

In accustomed-hand writing no difference was found between copied and dictated samples as well as between the writings of male and female writers. A considerable difference has been observed in the writings of right-handed and left-handed writers with respect to t-crossing. 
As Table 1 indicates, all the right-handed writers wrote the t-bar from left to right with their accustomed hand. No writer was found to write the t-bar from right to left except one male writer who wrote it in a mixed form with his accustomed right hand. On the other hand, in unaccustomed-hand writing, the majority of the writers wrote the t-bar from left to right and in mixed form; some of the writers were found to write it from right to left. As mentioned earlier, in the case of accustomed writings of the right-handed writers, t-crossing was written from left to right; but when they wrote with their unaccustomed hand, their neuromuscular co-ordination did not remain normal and they got confused while forming the stroke in the correct direction. That is why the t-bar was formed in both directions in the unaccustomed-hand writings of the right-handed writers. Franks ${ }^{16}$ examined the t-crossing in 52 right-handed and 17 lefthanded writers in their accustomed-hand writing and it was found that 50 right-handed writers formed the t-crossing from left to right, while left-handed writers showed variations; i.e. 10 writers formed the right to left t-crossing, whereas 6 writers formed the t-crossing from left to right. In the case of left-handed writers, the majority wrote the t-bar from left to right, while some (both male and female) wrote it from right to left, and in mixed form with the accustomed hand. It means that both types of t-crossing have been made by the left-handed writers with their accustomed hands. Saran et al. ${ }^{17}$ examined the cross strokes in 50 left-handed and 50 right-handed writers in their accustomed-hand writings, and the results showed that cross strokes of left-handed writers were made from right to left while cross stroke of right-handed writers were made from left to right. In the present study, the frequency of left-handed writers having t-crossing from right to left was found to be higher than that of the righthanded writers writing with their accustomed hands. It was observed that a writer has the habit of making horizontal strokes in right to left direction because of the use of the left hand.

16 J.E. Franks, "The direction of ballpoint pen strokes in left and right-handed writers as indicated by the orientation of burr striations", Journal of Forensic Science Society 22,1982 , no. 3, pp. 271-274.

17 V. Saran et al., "Differentiation of handedness of writer based on their strokes and characteristic features", Journal of forensic research 4, 2013, no. 5, pp. 1-3. 
Joseph $^{18}$ reported that left-handed writers cross the lower case letter ' $t$ ' from right to left. In the present study, the majority of left-handed writers cross the letter ' $t$ ' from left to right; but it is true that the frequency of right to left t-crossing was far higher in the case of left-handed writers as compared to the right-handed writers, in accustomed-hand writings, as is clear from Table 1. In the case of unaccustomed-hand writing, all lefthanded writers wrote the t-bar from left to right except one female writer who wrote it in a mixed form. No left-handed writer wrote the t-crossing in right to left direction with their unaccustomed hand. There is a natural tendency for most of the writers to make horizontal strokes from left to right. When a left-handed writer used their right hand as the unaccustomed hand, t-crossing stroke was automatically formed in left to right direction. Actually, the brain is divided into the right hemisphere and the left hemisphere. Right-handers (95-99\%) receive motor signals (hand, arm, wrist, etc.) and sensory signals (vision and touch) from the left hemisphere, while left-handers receive motor signals from the right hemisphere. In $60-70 \%$ left-handers, the faculty of language and speed is located in the left hemisphere. Hence, it is necessary for the impulses to travel from the left hemisphere to the right one to receive appropriate motor information by the left hand. ${ }^{19}$ This transfer of motor signals from the left hemisphere to the right hemisphere might be responsible for the left-handed writers making the stroke from right to left with their accustomed left hand. As mentioned above, no left-handed writer wrote the t-crossing in right to left direction with their unaccustomed hand. The reason for this may be that $60-70 \%$ left-handers receive motor signals from the left hemisphere and the left hemisphere virtually controls the right hand. When a left-handed writer writes with the right unaccustomed hand, they receive motor signals directly from the left hemisphere, as the right-handers do.

On the one hand, it was observed that when written with the unaccustomed hand, the shape of the t-crossing changed into a curved or wavy form; or sometimes it remained straight. On the other hand, it was found to be straight in the accustomed-hand writing - its direction goes either

18 J.A. Joseph, op. cit.

19 G.A. Dawson, "Brain function and writing...". 
upward or downward. Dawson examined the t-crossing in right-handed unaccustomed-hand writing and found that with the unaccustomed hand, the stroke was curved, straight, or wavy, but failed to determine the direction of t-crossing. Findings of the present study are also in accordance with the results reported by Dawson. The horizontal stroke of the t-bar was found to be curved, wavy, or straight when written with the unaccustomed hand. ${ }^{20}$

Table 1. T-crossing (right-handed and left-handed writers, 50 males and 50 females)

\begin{tabular}{|l|c|c|c|c|c|c|c|c|}
\hline \multirow{2}{*}{ Types } & \multicolumn{2}{|c|}{ Males } & \multicolumn{2}{c|}{ Females } & \multicolumn{2}{c|}{ Males } & \multicolumn{2}{c|}{ Females } \\
\cline { 2 - 9 } & $\mathrm{AC}$ & $\mathrm{AD}$ & $\mathrm{AC}$ & $\mathrm{AD}$ & $\mathrm{UC}$ & $\mathrm{UD}$ & $\mathrm{UC}$ & $\mathrm{UD}$ \\
\hline $\begin{array}{l}\text { Left } \\
\text { to right }\end{array}$ & $49(33)$ & $49(33)$ & $50(36)$ & $50(36)$ & $32(50)$ & $31(50)$ & $18(49)$ & $18(49)$ \\
\hline $\begin{array}{l}\text { Right } \\
\text { to left }\end{array}$ & $00(11)$ & $00(11)$ & $00(09)$ & $00(09)$ & $04(00)$ & $06(00)$ & $10(00)$ & $07(00)$ \\
\hline Mixed & $01(06)$ & $01(06)$ & $00(05)$ & $00(05)$ & $14(00)$ & $13(00)$ & $22(01)$ & $25(01)$ \\
\hline
\end{tabular}

Abbreviations used in tables

AC: Accustomed hand, normal writing

AD: Accustomed hand, disguised writing

UC: Unaccustomed hand, normal writing

UD: Unaccustomed hand, disguised writing

Diacritic mark over the letters ' $i$ ' and ' $j$ '

I-dot is a diacritic mark which is present over the letter ' $\mathrm{i}$ ' and the similar diacritic mark is also present over letter ' $\mathrm{j}$.' In the present context, diacritic on both the letters ' $i$ ' and ' $j$ ' will be called a diacritic only irrespective of the letter containing it. Different types of diacritic marks have been observed in handwritings of accustomed as well as unaccustomed hand and were classified as 'dot,' 'tick,' 'circle,' 'mixed,' and 'inverted-v,' which have been demonstrated through Figure 5 both in accustomed- and unaccustomed-hand writings. Table 2 shows different classes of i-dots in both the right-handed and left-handed writers.

${ }^{20}$ Ibid. 


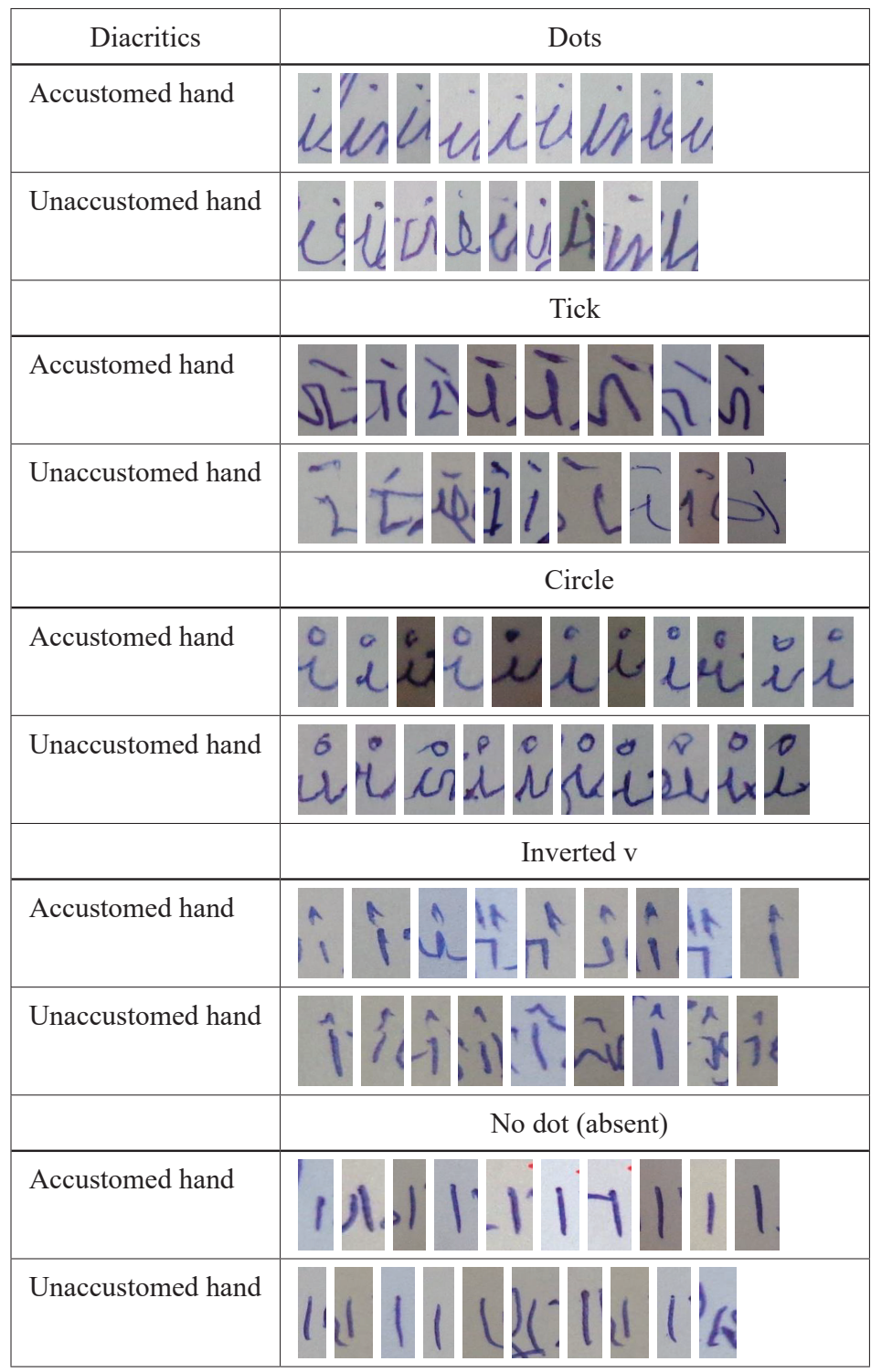




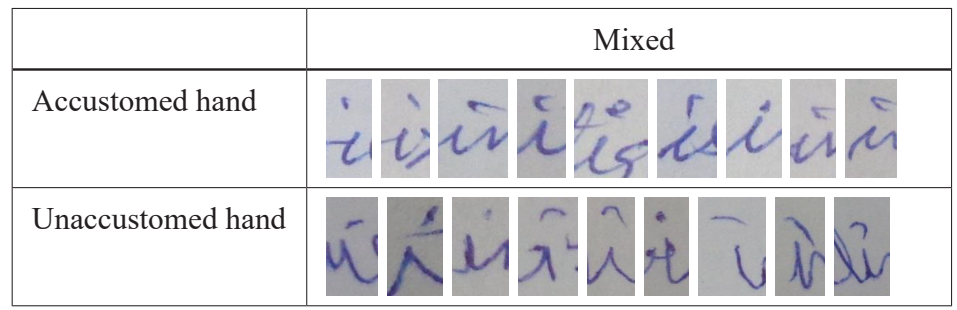

Figure 5. Various types of i-dots in accustomed- and unaccustomed-hand writings

As indicated in Table 2, 'dot' and 'mixed' types of diacritic were found to be the most common in all the writings irrespective of the writer's sex and the hand used for writing; though the dot type was observed more than the mixed type. This was found to be correct for both sexes as well as hands of writing. With the dot, the frequency increased further in the unaccustomed-hand writing.

In the case of accustomed-hand writing, not much variation has been observed in copying and dictation method of collecting writing samples. Results showed that 30-62\% writers made the diacritic in the form of a dot in both left-handed and right-handed handwritings with their accustomed hand. Around 20-50\% writers made the i-dot in mixed form, $6-14 \%$ writers made the $\mathrm{i}-\mathrm{dot}$ in the form of a 'tick,' and $4-6 \%$ writers made the i-dot in 'inverted v' form. As was already discussed, the 'tick' and 'inverted v' forms were found in very small numbers in accustomed hand. $6-26 \%$ writers made the i-dot in 'circle' form. Those subjects who do not have the habit of making any $\mathrm{i}$-dot were considered as absent. $6 \%$ writers do not form any diacritic mark over ' $i$ ' in accustomed-hand writing. The same subjects while writing with unaccustomed hand also did not form any diacritic mark over ' $i$.' With unaccustomed hand 44-92\% writers made a diacritic in the form of a dot in both left-handed and right-handed writings. Results showed that a diacritic mark in the form of a dot is most frequently used in unaccustomed-hand writing as compared to accustomed hand in both right-handed and left-handed writers. The probable reason could be that the writer was unable to make other types of i-dots easily except the 'dot' with their unaccustomed hand. Some of the writers have mixed i-dots in their unaccustomed-hand writing, and mixed i-dots mostly included only the dots and ticks. The 'inverted v' diacritic could not be found in unaccustomed-hand writings of any writer. 
Dawson $^{21}$ examined the i-dots in the writings of 20 right-handed writers. It was observed that with the unaccustomed hand, diacritics were placed either directly above, to the right, or to the left of 'i.' The shape of dots varies in left- and right-handed writings - commas, small vertical or horizontal slashes were made with unaccustomed hand, while these unusual shapes were rarely found in their right hand. It was also found that if a dot was not present in right-hand writing, then it was also not present in left-hand writing. In the present study it was also observed that if the writer had not placed any diacritics in their accustomed-hand writing, then they were not found in the unaccustomed hand writing either.

Table 2. Diacritic mark over 'i' (right-handed and left-handed writers, 50 males and 50 females)

\begin{tabular}{|l|c|c|c|c|c|c|c|c|}
\hline \multirow{2}{*}{ Types } & \multicolumn{2}{|c|}{ Males } & \multicolumn{2}{c|}{ Females } & \multicolumn{2}{c|}{ Males } & \multicolumn{2}{c|}{ Females } \\
\cline { 2 - 9 } & $\mathrm{AC}$ & $\mathrm{AD}$ & $\mathrm{AC}$ & $\mathrm{AD}$ & $\mathrm{UC}$ & $\mathrm{UD}$ & $\mathrm{UC}$ & $\mathrm{UD}$ \\
\hline Dot & $21(29)$ & $19(31)$ & $18(17)$ & $19(15)$ & $32(43)$ & $32(46)$ & $24(35)$ & $22(36)$ \\
\hline Tick & $07(07)$ & $07(03)$ & $03(03)$ & $03(03)$ & $00(01)$ & $02(00)$ & $02(00)$ & $02(01)$ \\
\hline Circle & $03(03)$ & $03(03)$ & $12(13)$ & $09(07)$ & $02(00)$ & $02(00)$ & $09(03)$ & $06(02)$ \\
\hline Mixed & $14(10)$ & $17(12)$ & $17(17)$ & $19(25)$ & $14(05)$ & $12(03)$ & $15(12)$ & $20(11)$ \\
\hline $\begin{array}{l}\text { Inverted } \\
\mathrm{v}\left({ }^{\wedge}\right)\end{array}$ & $03(00)$ & $02(00)$ & $00(00)$ & $00(00)$ & $00(00)$ & $00(00)$ & $00(00)$ & $00(00)$ \\
\hline Absent & $02(01)$ & $02(01)$ & $00(00)$ & $00(00)$ & $02(01)$ & $02(01)$ & $00(00)$ & $00(00)$ \\
\hline
\end{tabular}

\section{Letter 'o'}

Letter'o'is drawnin the form of a circleoroval which can be constructed in two ways; namely, anti-clockwise or clockwise. Most of the people write the letter ' $\mathrm{o}$ ' anti-clockwise; therefore, it can be considered the normal way of writing, although writing the letter 'o' clockwise is also observed. In addition to this, some writers may write the letter ' $\mathrm{o}$ ' in both directions. In the present study the letter 'o' with anti-clockwise move-

21 Ibid. 
ment was also found to be the most frequent type. The results of the study are presented in Table 3.

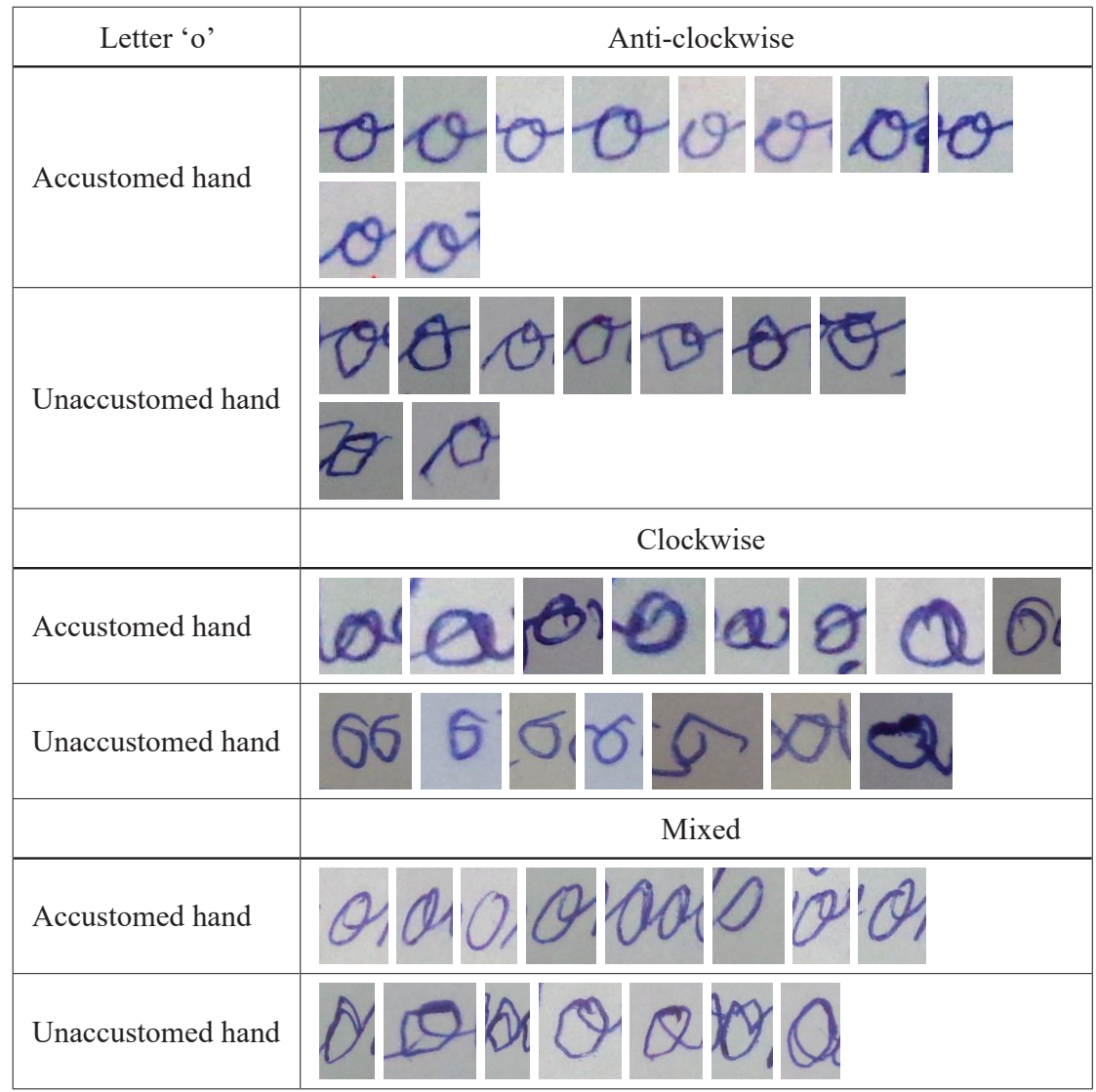

Figure 6. Different classes of the letter 'o' in accustomed- and unaccustomed-hand writings

Table 3 indicates that in accustomed hand writing, majority of righthanders wrote letter 'o' anti-clockwise. One male and one female writer wrote the letter 'o' clockwise in both copied and dictated samples. Not much variation was observed in copied and dictated samples. Male and female writers also do not show any significant differences in both left- and right-handed writers. The frequency of left-handed writers writing the let- 
ter 'o' clockwise was quite high ( 7 males and 5 females) as compared to the right-handed writers. The majority wrote the letter ' $\mathrm{o}$ ' anti-clockwise (40 males and 43 females) and two writers wrote it in both directions in mixed type. Talbot-Wilson ${ }^{22}$ estimated that $42 \%$ left-handed and $1 \%$ right-handed writers wrote the circular strokes in a clockwise manner. Franks ${ }^{23}$ examined the letter 'o' in 52 right-handed and 17 left-handed writers in their accustomed-hand writing. It was found that all righthanded writers formed the letter 'o' anti-clockwise, while left-handed writers showed variations, i.e. 10 writers formed it anti-clockwise, while 7 writers - clockwise. These findings are in accordance with the studies reported earlier. In the present study, as discussed above, the majority of right-handed writers formed the letter 'o' anti-clockwise, while lefthanded writers showed variation in clockwise and anti-clockwise accustomed hand movement. At the same time, in the case of unaccustomedhand writing the majority of the writers wrote the letter 'o' anti-clockwise (approximately 33 right-handed and 44 left-handed writers) irrespective of their dominant hand. Two left-handed female writers were found to have written the letter 'o' clockwise, while five right-handed writers ( 3 male and 2 female) wrote it clockwise with the unaccustomed hand. The frequency of the letter ' $\mathrm{o}$ ' in both directions (mixed type) was higher in the case of right-handed writers as compared to the lefthanded ones in unaccustomed-hand writings. This observation clearly indicates that the anti-clockwise formation of the letter 'o' can be seen as the most natural and ergonomic one for a writer. The preferred anticlockwise trend could also be seen in unaccustomed-hand writing, indicating the fixed writing habit of the writer concerned. There was a visible increase of mixed type (both types) letter 'o' formation in unaccustomedhand writings particularly in right-handed writers. This may be due to the inadequate neuromuscular co-ordination with the unaccustomed hand, which thus creates confusion in making out the correct direction in forming the letter 'o.'

22 M.G. Talbot-Wilson, "Variability of stroke direction between left- and righthanded writers", Journal of the Forensic Science Society 26, 1986, no. 3, pp. 177-179.

23 J.E. Franks, op. cit. 
Table 3. The letter 'o' (right-handed and left-handed writers, 50 males and 50 females)

\begin{tabular}{|l|c|c|c|c|c|c|c|c|}
\hline \multirow{2}{*}{ Types } & \multicolumn{2}{|c|}{ Males } & \multicolumn{2}{c|}{ Females } & \multicolumn{2}{c|}{ Males } & \multicolumn{2}{c|}{ Females } \\
\cline { 2 - 9 } & AC & AD & AC & AD & UC & UD & UC & UD \\
\hline $\begin{array}{l}\text { Anti- } \\
\text { clockwise }\end{array}$ & $49(41)$ & $49(40)$ & $49(43)$ & $49(43)$ & $32(44)$ & $32(42)$ & $30(43)$ & $33(41)$ \\
\hline Clockwise & $01(07)$ & $01(07)$ & $01(05)$ & $01(05)$ & $03(00)$ & $03(00)$ & $02(02)$ & $02(02)$ \\
\hline Mixed & $00(02)$ & $00(03)$ & $00(02)$ & $00(02)$ & $15(06)$ & $15(08)$ & $18(05)$ & $15(07)$ \\
\hline
\end{tabular}

Conrad $^{24}$ examined the direction of the letter ' $\mathrm{o}$ ' in 30 left-handers and 30 right-handers in accustomed-hand writings in order to establish the handedness of the writer, and classified the letter ' $\mathrm{o}$ ' into three types: counterclockwise, clockwise, and a combination of counterclockwise and clockwise. The results showed that most writers in both the groups wrote circular strokes in counter-clockwise direction: $13.3 \%$ left-handed writers used clockwise circles, while a combination of both movements was seen only in left-handed writers. In the present study results show consistency with Conrad's findings. Left-handed as well as right-handed writers wrote the letter ' $o$ ' in anti-clockwise direction, in majority of the cases, in copied as well as dictated samples of accustomed writing. Very few writers wrote this letter clockwise; whereas negligibly small number wrote the letter 'o' with mixed type of movement. As evident from Table 4, in the case of unaccustomed writing, forming the letter 'o' anticlockwise remained the preferred choice; however, its numbers decreased significantly when the element of disguise was brought in. At the same time, the frequency of the clockwise direction remained unaffected by the introduction of disguise. The decrease in the number of those writing in anticlockwise direction was probably due to the shifting of such writers to the mixed category - the same writer writing the letter ' $\mathrm{o}$ ' in both the clockwise and anticlockwise directions. The results of the study indicate a writer's weakening neuromuscular coordination due to the change of the writing hand.

24 M. Conrad, op. cit. 
Table 4. The formation of letter 'o' (right-handed and left-handed writers, 50 males and 50 females)

\begin{tabular}{|l|c|c|c|c|c|c|c|c|}
\hline \multirow{2}{*}{ Types } & \multicolumn{2}{|c|}{ Males } & \multicolumn{2}{c|}{ Females } & \multicolumn{2}{c|}{ Males } & \multicolumn{2}{c|}{ Females } \\
\cline { 2 - 9 } & $\mathrm{AC}$ & $\mathrm{AD}$ & $\mathrm{AC}$ & $\mathrm{AD}$ & $\mathrm{UC}$ & $\mathrm{UD}$ & $\mathrm{UC}$ & $\mathrm{UD}$ \\
\hline $\begin{array}{l}\text { Anti- } \\
\text { clockwise }\end{array}$ & $49(41)$ & $49(40)$ & $49(43)$ & $49(43)$ & $32(44)$ & $32(42)$ & $30(43)$ & $33(41)$ \\
\hline Clockwise & $01(07)$ & $01(07)$ & $01(05)$ & $01(05)$ & $03(00)$ & $03(00)$ & $02(02)$ & $02(02)$ \\
\hline Mixed & $00(02)$ & $00(03)$ & $00(02)$ & $00(02)$ & $15(06)$ & $15(08)$ & $18(05)$ & $15(07)$ \\
\hline
\end{tabular}

Generally, the letter ' $\mathrm{o}$ ' is long, elliptical, and round when written with the dominant hand. But when the writer uses their unaccustomed hand, it affects the shape of this letter; i.e. angular or squarish shapes are observed, the direction of the letter ' $\mathrm{o}$ ' is changed, as was discussed earlier. Normally, its opening and closing location is on the upper side, but with the unaccustomed hand its opening and closing location are sometimes changed to the lower side, which is illustrated through Figure 7. It shows the opening and closing locations of the letter ' $\mathrm{o}$ ' in both the accustomed and unaccustomed hand, which clearly indicates the differences that occur due to the use of the unaccustomed hand.

\begin{tabular}{|c|c|c|}
\hline S.No. & Accustomed hand & Unaccustomed hand \\
\hline 1. & & \\
\hline 2. & $b 0 \times$ & \\
\hline 3. & boxing & $y$ \\
\hline 4. & Jomen & Noraper \\
\hline 5. & & \\
\hline
\end{tabular}

Figure 7. The opening and closing location of the letter 'o' in the accustomed and unaccustomed hand

Nowa Kodyfikacja Prawa Karnego 59, 2021

(C) for this edition by CNS 


\section{Conclusion}

It is said that handwriting characteristics of an individual, even over a period of time and under varying conditions, remain similar; and whatever differences are observed remain within the range of natural variation. This means all the usual handwriting variations of an individual, as a rule, will fit into a master pattern; but in the case of unaccustomed-hand writing by the same person there is an exception that may not always follow the said pattern. Such an exception may jeopardize the observations made by a forensic examiner and result in an erroneous conclusion if adequate precautions are not taken. The results of the study indicate that, despite the change in pictorial appearance, the connecting strokes between letters still remained intact; and in combination with more such features, they could form the basis of identification of the unaccustomedhand writing. The possibility of using the unaccustomed hand as a mode of disguise must always be kept in mind by the examiner while handling such problems involving unnatural handwriting produced by a writer's unaccustomed hand. In such cases, the examiner may study and evaluate several unconscious features that are rarely disguised, including the connecting strokes of letters that appear to be formed irrespective of the writer's handedness. The identification of writings disguised with the use of the unaccustomed hand is a difficult task; unless a sufficient number of unconscious lapses of the writer is found between the questioned and the standard writings, a definite opinion regarding their common or different authorship may not be possible.

Although there may be certain similarities in the formation of several handwritten strokes, due to the presence of usual unaccustomed hand characteristics in the questioned disguised writings - such as angularity, hesitations, abrupt directional changes, hair line connections, uncertain movements, as well as tremulous strokes - it is not safe to make conclusions about the authorship of that writing. 


\section{References}

Alford E.F., "Disguised handwriting: A statistical survey of how handwriting is most frequently disguised", Journal of Forensic Science 15, 1970, no. 4.

Anita, Jasuja O.P., "Mirror writing: A trait of writing with unaccustomed hand", Problems of Forensic Science 106, 2016.

Conrad M., "Left-hand writing vs. right-hand writing", Journal of the American Society of Questioned Document Examiners 11, 2008, no. 1.

Dawson G.A., "An identification of handprinting produced with the unaccustomed left hand", Canadian Society of Forensic Science Journal 26, 1993, no. 2.

Dawson G.A., "Brain function and writing with the unaccustomed left hand", Journal of Forensic Science 30, 1985, no. 1.

Dziedzic T., "Right hand writing vs. left hand writing of one person: A comparative study", Problems of Forensic Sciences 94, 2013.

Dziedzic T., "The development of left-handed writing features of a right-handed person who has undertaken training in writing with his left hand", Problems of Forensic Sciences 83, 2011.

Franks J.E., "The direction of ballpoint pen strokes in left- and right-handed writers as indicated by the orientation of burr striations", Journal of Forensic Science Society 22, 1982 , no. 3 .

Franks J.E. et al., "Variability of stroke direction between left- and right-handed writers", Journal of the Forensic Science Society 25, 1985, no. 5.

Harrison W.R., Suspect documents: Their scientific examination, London 1958.

Hilton O., Scientific examination of questioned documents, New York 1982.

Huber R.A., Headrick A.M., Handwriting identification: facts and fundamentals, Boca Raton, FL 1999.

Jones M., "10 fascinating facts you never knew about ambidextrous people", Reader's Digest, 29.05.2019, https://www.rd.com/list/facts-ambidextrous-people/.

Joseph J.A., "Left-hand and opposite-hand writing features useful as a basis of forming expert opinions of authorship", National Association of Document Examiners Journal 2004.

Kelly J.S., Lindblom B.S., Scientific examination of questioned documents, Boca Raton, FL 2006.

Kerns Geer K., “12 little known facts about left-handers”, Everyday Health, 13.08.2015, https://www.everydayhealth.com/healthy-living-pictures/little-known-facts-aboutlefthanders.aspx.

Koppenhaver K.M., Forensic document examination: Principles and practice, Totowa, NJ 2007.

Osborn A.S., Questioned documents, Rochester, NY 1929.

Saran V. et al., "Differentiation of handedness of writer based on their strokes and characteristic features", Journal of forensic research 4, 2013, no. 5.

Talbot-Wilson M.G., "Variability of stroke direction between left- and right-handed writers", Journal of the Forensic Science Society 26, 1986, no. 3. 